\title{
Effect of Metal-Metal Interactions on Electron Transfer: an STM Study of One-Dimensional Metal String Complexes
}

\author{
Shu-Yi Lin, ${ }^{\dagger}$ I-Wen Peter Chen, ${ }^{\dagger}$ Chun-hsien Chen, ${ }^{*}, \dagger$ Ming-Hsun Hsieh,,+ Chen-Yu Yeh,,$\$$ \\ Tzu-Wei Lin, $\$$ Yu-Hua Chen, $\$$ and Shie-Ming Peng*,,$\perp$ \\ Department of Chemistry, National Tsing Hua University, Hsinchu, Taiwan 30013, \\ Department of Chemistry, National Taiwan University, Taipei, Taiwan 106, and Institute of Chemistry, \\ Academia Sinica, Taipei, Taiwan 115
}

Received: May 22, 2003; In Final Form: November 3, 2003

\begin{abstract}
Linear metal string complexes of $\left[\mathrm{M}_{n} \mathrm{~L}_{4}(\mathrm{NCS})_{2}\right]$ (Scheme $1, \mathrm{M}=\mathrm{Ni}^{\mathrm{II}}, \mathrm{Co}^{\mathrm{II}}$, or $\mathrm{Cr}{ }^{\mathrm{II}} ; n=3$ or $5 ; \mathrm{L}^{2}=\mathrm{dpa}^{-}$or $\mathrm{tpda}^{2-}$ where $\mathrm{dpa}^{-}$is dipyridylamido anion and $\mathrm{tpda}^{2-}$ is tripyridyldiamido dianion) are studied for the fundamental understanding of the effect of inter-nuclei interactions on electron transfer (ET). The metal strings are isolated within $n$-alkanethiol monolayers and the properties of ET through various metal strings are differentiated by scanning tunneling microscopy. Although very similar in physical dimension, their apparent heights against the same alkanethiol background are significantly different. The discrepancy is ascribed to electron localization-delocalization among the metal centers.
\end{abstract}

\section{Introduction}

Studies of metal string complexes such as those sketched in Scheme 1 have been an important subject in the fundamental research of metal-metal interactions ${ }^{1-25}$ and have attracted considerable attention due to the potential applications of the complexes as molecular metal wires. Structural characterization by X-ray diffraction reveals that the metal ions are collinear and wrapped helically with four ligands. ${ }^{1-3,5-22}$ Synthetic effort of lengthening the ligands ${ }^{26}$ and the metal complexes has been making progress. Currently, a string of 9 nickel ions (i.e., $m=$ 3 in Scheme 1), equivalent to a ca. 3-nm long string, has been successfully engineered, ${ }^{3}$ advancing further toward molecular wires for nanoscale devices. An essential property for becoming a new class of material practical for nanotechnology is having good electrical conductivity. Although conductance of organic molecules with ${ }^{27-34}$ and without ${ }^{34-40} \pi$-electron conjugated system as well as metalated phthalocyanines ${ }^{41,42}$ or porphyrins ${ }^{43}$ monolayers has been investigated down to the molecular level, this is yet unexplored for the metal string complexes, in which the electrons are likely to transfer through the metal centers.

In this study, we demonstrate that manipulation of the electron-transfer (ET) properties of the molecular wires is feasible by rational design and fine-tune of the metal-metal interactions. For instance, Cotton et al. ${ }^{12-14}$ and our group ${ }^{8}$ have proposed that the ET efficiency should be determined by the number of delocalized electrons at the metal centers. In this current study, with the axial ligands of isothiocyanate shown in Scheme 1, the neutral metal string complexes exhibit symmetric metal-metal distances. ${ }^{5-8,21}$ (Note that with other

* To whom correspondence should be addressed. (S.-M. P.) Phone: +886 22363 8305. Fax: +88622363 6359. E-mail: smpeng@mail.ch.ntu.edu.tw. (C.-h.C.) Phone: +8863573 7009. Fax: +886 3571 1082. E-mail: chhchen@mx.nthu.edu.tw.

National Tsing Hua University.

$\doteqdot$ National Taiwan University University.

$\S$ Present address: Department of Chemistry, National Chung-Hsing University, Taichung 40227, Taiwan, R.O.C.

$\perp$ Academia Sinica.

\section{SCHEME 1}

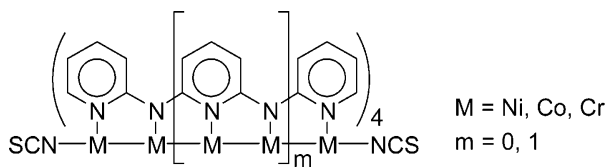

Notation for the ligand: $\mathrm{dpa}^{-}$, dipyridylamido anion $(m=0)$; $\operatorname{tpda}^{2-}$, tripyridyldiamido dianion $(m=1)$.

axial ligands and under the influence of crystallization environments and conditions, unsymmetric metal-metal distances have been reported. ${ }^{1,13-19}$ ) The internuclei interactions can then be adjusted by one-electron oxidation, ${ }^{7-13}$ and their electron configurations between states of localization and delocalization are thus regulated. Therefore, an on/off switch-like behavior associated with the neutral-oxidized states of the complexes is proposed. ${ }^{8,9,12,13}$ However, still lacking is a direct evidence in correlation of their ET properties with bond orders and with localization-delocalization states. To this end, we assess qualitatively their ET efficiency at single molecular level, following the STM (scanning tunneling microscopy) methodology, developed by Allara, Tour, and Weiss et al., ${ }^{27}$ with STM imaging of the metal string complexes isolated within $n$-dodecanethiol or $n$-decanethiol monolayers. In constant-current mode of STM operation, the tunneling current is kept constant by adjusting the height of the scanner at each measurement point with a feedback loop. The topography of STM images represents the electronic density of states or constant tunneling probability at the surface. For example, the metal string complexes exhibit enhanced contrast against the surrounding alkanethiol matrix due to the fact that their ET probabilities are higher than that of the alkanethiols. In the following section, the relative ET probabilities between the complexes are compared by the apparent heights against the same alkanethiol background. We will show that their ET properties are strongly influenced by their electronic configurations and by the number of delocalized electrons among the metal centers. 


\section{Experimental Section}

Chemical Materials. All chemical were reagent grade and were used as received unless otherwise noted. Dichloromethane used for electrochemical preparation of oxidized complexes was dried over $\mathrm{CaH}_{2}$ and freshly distilled prior to use. Tetra- $n$ butylammonium perchlorate (TBAP) was recrystallized twice from ethyl acetate and further dried under vacuum. Preparation methods for $\mathrm{H}_{2}$ tpda, ${ }^{5,6}\left[\mathrm{Ni}_{5}\left(\mu_{5} \text {-tpda }\right)_{4}(\mathrm{NCS})_{2}\right],{ }^{6}\left[\mathrm{Co}_{5}\left(\mu_{5} \text {-tpda }\right)_{4}-\right.$ $\left.(\mathrm{NCS})_{2}\right],{ }^{5,8}\left[\mathrm{Cr}_{5}\left(\mu_{5} \text {-tpda }\right)_{4}(\mathrm{NCS})_{2}\right],{ }^{7}$ and $\left[\mathrm{Co}_{5}\left(\mu_{5} \text {-tpda }\right)_{4}(\mathrm{NCS})_{2}\right]-$ $\left(\mathrm{ClO}_{4}\right)^{8}$ were the same as the procedures reported previously.

Preparation of $\left[\mathbf{N i}_{3}\left(\boldsymbol{\mu}_{\mathbf{3}}-\mathbf{d p a}\right)_{\mathbf{4}}(\mathbf{N C S})_{2}\right]$. Ligand Hdpa $(0.204$ $\mathrm{g}, 1.20 \mathrm{mmol}), \mathrm{NiCl}_{2}(0.144 \mathrm{~g}, 1.1 \mathrm{mmol})$, and $30 \mathrm{~g}$ naphthalene (as solvent) were placed in an 50-mL Erlenmeyer flask and the mixture was heated and stirred at $150{ }^{\circ} \mathrm{C}$ for $3 \mathrm{~h}$ to remove water. After an increase of temperature to $180{ }^{\circ} \mathrm{C}, t$-BuOK $(0.156 \mathrm{~g}, 1.6 \mathrm{mmol})$ in $10 \mathrm{~mL}$ of $n-\mathrm{BuOH}$ was added dropwise. Afterward, the solution was severely refluxed until about 10 $\mathrm{mL}$ of naphthalene was left. The mixture was then cooled to room temperature. Hexane was added and the mixture was filtered. The solid was extracted with $\mathrm{CH}_{2} \mathrm{Cl}_{2}$. The solution was removed by a rotary evaporator till $50 \mathrm{~mL}$ to which excess $\mathrm{NaSCN}$ was added and stirred for 2 days. The mixture was filtered and washed with $\mathrm{CH}_{2} \mathrm{Cl}_{2}$ until the residue appeared white. The product was in solution phase and was collected by removal of $\mathrm{CH}_{2} \mathrm{Cl}_{2}$ with a rotary evaporator. Deep-purple crystals of $\left[\mathrm{Ni}_{3}\left(\mu_{3} \text {-dpa }\right)_{4}(\mathrm{NCS})_{2}\right]$ were obtained by recrystallization from $\mathrm{CH}_{2} \mathrm{Cl}_{2}$ and hexane.

Preparation of $\left[\mathrm{Co}_{3}\left(\boldsymbol{\mu}_{3}-\mathrm{dpa}\right)_{4}(\mathrm{NCS})_{2}\right]$. This complex has been prepared by Cotton, Murillo, and co-workers and found three different solvated crystals. ${ }^{21}$ The compound used here was prepared by the following procedures. Ligand Hdpa (0.204 g, $1.20 \mathrm{mmol}), \mathrm{CoCl}_{2}(0.144 \mathrm{~g}, 1.1 \mathrm{mmol})$, and $20 \mathrm{~g}$ of naphthalene (as solvent) were placed in an 50-mL Erlenmeyer flask, and the mixture was heated and stirred at $150{ }^{\circ} \mathrm{C}$ for $3 \mathrm{~h}$ to remove water. A procedure similar to that for $\left[\mathrm{Ni}_{3}\left(\mu_{3} \text {-dpa }\right)_{4}(\mathrm{NCS})_{2}\right]$ was employed. The color was beige for the precipitate after removal of naphthalene, brown for the solution after extraction with $\mathrm{CH}_{2}$ $\mathrm{Cl}_{2}$, and brown after crystallization.

Preparation of $\left[\mathrm{Cr}_{3}\left(\boldsymbol{\mu}_{3} \text {-dpa }\right)_{4}(\mathbf{N C S})_{2}\right] .{ }^{4}$ Ligand Hdpa $(0.5$ $\mathrm{g}, 3 \mathrm{mmol}$ ) and $20 \mathrm{~g}$ of naphthalene (as solvent) were placed in a $125-\mathrm{mL}$ Erlenmeyer flask to which $\mathrm{CrCl}_{2}(0.36 \mathrm{~g}, 3 \mathrm{mmol})$ and $t$-BuOK $(0.33 \mathrm{~g}, 3 \mathrm{mmol})$ was added in a glovebox. The mixture was heated and stirred at $180{ }^{\circ} \mathrm{C}$ under an argon atmosphere for $12 \mathrm{~h}$. The solution was then gently refluxed at $220{ }^{\circ} \mathrm{C}$ for $2 \mathrm{~h}$. The mixture was cooled to room temperature. Hexane was added, and deep-brown solid precipitates were filtered to remove naphthalene. After extraction with $\mathrm{CH}_{2} \mathrm{Cl}_{2}$, the solution appeared red-brown and was removed by a rotary evaporator till $50 \mathrm{~mL}$ to which excess $\mathrm{NaSCN}$ was added and stirred for 2 days. The mixture was filtered and washed with $\mathrm{CH}_{2} \mathrm{Cl}_{2}$ until the residue appeared white. The product was in solution phase and was collected by removal of $\mathrm{CH}_{2} \mathrm{Cl}_{2}$ with a rotary evaporator. Red crystals of $\left[\mathrm{Cr}_{3}\left(\mu_{3} \text {-dpa }\right)_{4}(\mathrm{NCS})_{2}\right]$ were obtained by crystallization from $\mathrm{CH}_{2} \mathrm{Cl}_{2}$ and hexane.

Preparation of $\left[\mathrm{Ni}_{5}\left(\mu_{5} \text {-tpda }\right)_{4}(\mathrm{NCS})_{2}{ }^{+}\right]\left(\mathrm{ClO}_{4}{ }^{-}\right)$. Note that insertion of the complex onto the preadsorbed alkanethiol SAMs for STM measurements was taking place immediately after the electrochemically oxidized form was generated. One-electron oxidized penta-nuclear complexes were prepared by electrolysis which was carried out with a PAR VersaStat (EG\&G Instruments Corp., Princeton, NJ). The preparation solution was 1 $\mathrm{mM}\left[\mathrm{Ni}_{5}\left(\mu_{5} \text {-tpda }\right)_{4}(\mathrm{NCS})_{2}\right]$ in $20-\mathrm{mL}$ of dry $\mathrm{CH}_{2} \mathrm{Cl}_{2}$ containing $0.1 \mathrm{M}$ TBAP. A silver wire deposited with $\mathrm{AgCl}(\mathrm{s})$ was employed as the quasi-reference electrode. The working and counter electrodes were both Pt mesh with dimensions about 1 $\mathrm{cm}^{2}$. The cell was a conventional $\mathrm{H}$-shape glass cell with a porous frit to separate the compartments of working and counter electrodes where the solution in the latter did not contain $\left[\mathrm{Ni}_{5^{-}}\right.$ $\left.\left(\mu_{5} \text {-tpda }\right)_{4}(\mathrm{NCS})_{2}\right]$. Electrolysis was taking place at $E_{\text {appl }}=0.85$ $\mathrm{V}$ vs $\mathrm{Ag} / \mathrm{AgCl}$ for $30 \mathrm{~min}$ and the solution was stirred throughout the experiment under $\mathrm{N}_{2}$ environment. The solution was then transferred quickly to a sample vial where the sample was prepared by immersion of gold substrates with preadsorbed alkanethiol SAMs

Preparation of $\left[\mathrm{Cr}_{5}\left(\mu_{5} \text {-tpda }\right)_{4}(\mathrm{NCS})_{2}{ }^{+}\right]\left(\mathrm{ClO}_{4}{ }^{-}\right)$. $\left[\mathrm{Cr}_{5}\left(\mu_{5^{-}}\right.\right.$ tpda) $\left.)_{4} \mathrm{Cl}_{2}\right]^{7}(0.1 \mathrm{~g}, 0.072 \mathrm{mmol})$ was dissolved in $100 \mathrm{~mL}$ of $\mathrm{CH}_{2} \mathrm{Cl}_{2}$ with the aid of sonication for $30 \mathrm{~min}$ in a $250-\mathrm{mL}$ round bottle flask. To the solution was added $2 \mathrm{~mL}$ of methanol containing $80 \mathrm{mg}$ of $\mathrm{Ag}(\mathrm{OTf})$ (siver trifluoromethanesulfonate). After 5 min of stirring, the solution was filtered to remove $\mathrm{AgCl}$ and Ag solid. After the solution was mixed with $\mathrm{NaSCN}(1 \mathrm{~g})$ and stirred for $45 \mathrm{~min}$, solvent was removed with a rotary evaporator. The residue was dissolved in $\mathrm{CH}_{2} \mathrm{Cl}_{2}$ and washed with deionized water and saturated aqueous $\mathrm{KClO}_{4}$, successively. The organic layer was dried over $\mathrm{Na}_{2} \mathrm{SO}_{4}$ and concentrated under reduced pressure. Red-brown crystals of $\left[\mathrm{Cr}_{5}\left(\mu_{5^{-}}\right.\right.$ tpda $\left.)_{4}(\mathrm{NCS})_{2}{ }^{+}\right]\left(\mathrm{ClO}_{4}{ }^{-}\right)$were obtained by crystallization from $\mathrm{CH}_{2} \mathrm{Cl}_{2}$ and hexane.

STM Measurements. The $\mathrm{Au}(111)$ substrates (Gold arrandee, purchased from Metallhandel Schroer GmbH, Germany) were $\sim 200-300 \mathrm{~nm}$ thick gold films with a $\sim 1-4 \mathrm{~nm}$ thick $\mathrm{Cr}$ adhesive layer and were flame-annealed a few times before each experiment. The mixed monolayers were prepared by insertion of the metal string complexes into pre-assembled $n$-alkanethiol monolayers where the soaking solutions were 1 $\mathrm{mM}$ solutes dissolved in ethanol for $n$-alkanethiols and dichloromethane for the complexes. We found that among common organic solvents dichloromethane seemed the only one that allowed insertion of the metal string complexes while maintaining the alkanethiol molecules well ordered. STM measurements were carried out with a NanoScope II (Digital Instruments, Santa Barbara, CA) using a low-current scanning head (model HD0.5I), which had an adjustable resistor to obtain a higher tunneling impedance. Commercial Pt/Ir tips (Nanotips, Digital Instruments, Santa Barbara, CA) were employed. Typical imaging conditions of tunneling current and bias voltage were ranged from 10 to $15 \mathrm{pA}$ and from 1.2 to $2 \mathrm{~V}$, respectively. The microscope was housed in a chamber where dry $\mathrm{N}_{2}$ was purging throughout the experiments and the humidity was lower than $2 \%$.

IR Characterization. Transmission IR spectra of the metal string complexes were obtained by $\mathrm{KBr}$-pelleted samples. For spectra of monolayer films, the substrates were 200-nm-thick gold films thermally evaporated onto glass slides pre-cleaned with piranha solution which is a $1: 3(\mathrm{v} / \mathrm{v})$ mixture of $30 \% \mathrm{H}_{2} \mathrm{O}_{2}$ and concentrated $\mathrm{H}_{2} \mathrm{SO}_{4}$. This solution reacts violently with organic materials and should be handled with great care. The pressure in the bell-jar evaporator (Auto 306, Edwards High Vacuum International, West Sussex, UK) was nominally $3 \times$ $10^{-6}$ Torr. A 5-nm $\mathrm{Cr}$ underlayer was used to enhance the adhesion of the gold film. Absorption spectroscopy was carried out with a Perkin-Elmer System 2000 infrared spectrometer equipped with an MCT detector cooled with liquid nitrogen. The measurement scheme ${ }^{44}$ was a single reflection mode, and the $p$-polarized light was incident at $85^{\circ}$ from the surface normal with a grazing angle accessory (FT-85, Spectra-Tech, Shelton, CT). The light path, detector, and sample chambers were purged with dry nitrogen. 1024 scans of both the sample and the 

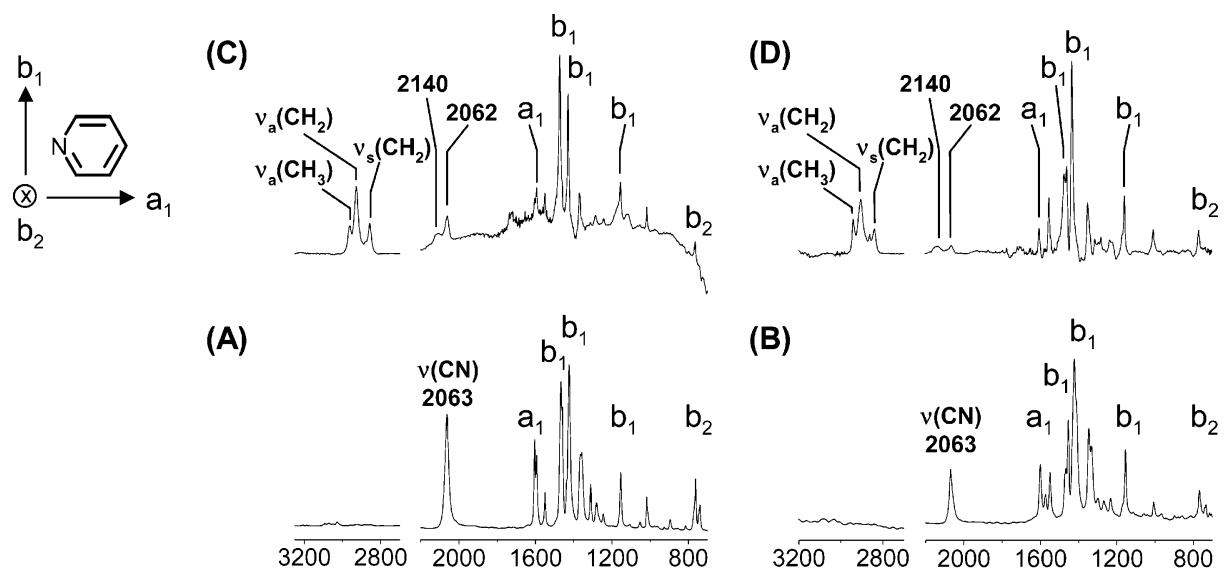

wavenumber $\left(\mathrm{cm}^{-1}\right)$

Figure 1. Transmission IR spectra of (A) $\left[\mathrm{Ni}_{3}\left(\mu_{3} \text {-dpa }\right)_{4}(\mathrm{NCS})_{2}\right]$ and $(\mathrm{B})\left[\mathrm{Ni}_{5}\left(\mu_{5} \text {-tpda }\right)_{4}(\mathrm{NCS})_{2}\right]$ prepared in $\mathrm{KBr}$ pellets and IRAS spectra of $(\mathrm{C})$ $\left[\mathrm{Ni}_{3}\left(\mu_{3}-\mathrm{dpa}\right)_{4}(\mathrm{NCS})_{2}\right]$ and (D) $\left[\mathrm{Ni}_{5}\left(\mu_{5} \text {-tpda }\right)_{4}(\mathrm{NCS})_{2}\right]$ containing films prepared in $n$-dodecanethiol preadsorbed gold substrate.

reference (bare $\mathrm{Au})$ were collected at $4-\mathrm{cm}^{-1}$ resolution for signal averaging.

\section{Results and Discussion}

Typical IR spectra of tri-nickel and penta-nickel complexes prepared in $\mathrm{KBr}$ pellets by transmission IR are shown, respectively, in Figure 1, parts $\mathrm{A}$ and $\mathrm{B}$, where the characteristic vibrational peaks for thiocyanate $\left(v_{\mathrm{CN}} \sim 2063 \mathrm{~cm}^{-1}\right)^{6}$ and the pyridyl moiety $\left(a_{1}, b_{1}, b_{2}\right)^{45,46}$ are denoted. Figure 1 , parts $C$ and $\mathrm{D}$, is the monolayer IRAS spectra (infrared reflectionabsorption spectroscopy) of tri-nickel and penta-nickel complexes prepared by insertion onto dodecanethiol (C12SH) preassembled polycrystalline gold substrate. The aliphatic peaks at $2850 \sim 2965 \mathrm{~cm}^{-1}$ arise from the matrix of dodecanethiol SAMs. The vibrational peak of the two axial ligands splits, indicating that one of the thiocyanates is S-bonded to the $\mathrm{Au}$ substrate $\left(v_{\mathrm{CN}} \sim 2140 \mathrm{~cm}^{-1}\right)^{47}$ and the other remains uncoordinated $\left(v_{\mathrm{CN}} \sim 2063 \mathrm{~cm}^{-1}\right)$.

For the convenience of the following discussion, defined in the left of Figure 1 are the transition dipoles of the pyridyl moiety. $\mathrm{a}_{1}\left(\sim 1600 \mathrm{~cm}^{-1}\right)$ and $\mathrm{b}_{1}\left(\sim 1460, \sim 1425, \sim 1155 \mathrm{~cm}^{-1}\right)$ are in-plane vibrational modes and are, respectively, parallel and perpendicular to the $C_{2}$ axis of this group; $\mathrm{b}_{2}\left(\sim 765 \mathrm{~cm}^{-1}\right)$ is an out-of-plane mode. ${ }^{45,46}$ The intensity ratios of $b_{1}$ to $a_{1}$ and $b_{1}$ to $b_{2}$ attenuate significantly between the corresponding samples prepared in $\mathrm{KBr}$ pellets and on monolayer films. Because the peak intensities obtained from $\mathrm{KBr}$ pellets represent transition dipoles oriented isotropically and because IRAS is insensitive to the transition dipole parallel to the surface plane, ${ }^{44,48}$ the decrease in intensities of $a_{1}$ and $b_{2}$ relative to that of $b_{1}$ suggests that the orientation of the polypyridyl ligands (and thus the metal strings) are standing toward surface normal, rather than lying flat on surface.

To estimate the tilt angles of the metal string complexes relative to the surface normal, their structures on the Au surface are assumed identical to those found in crystal forms. From their crystallographic structures, ${ }^{4-7}$ the angles between the axis of metal cores and the directions normal to the pyridyl ring planes are $68^{\circ}$ and $72^{\circ}$ for tri-nickel complex and $71^{\circ}, 72^{\circ}$, and $73^{\circ}$ for penta-nickel one. ${ }^{49}$ The intensity ratio of $b_{1}$ to $a_{1}$, after normalization by those of $\mathrm{KBr}$ samples, is used to estimate the molecular tilt angles which are determined $22^{\circ}-30^{\circ}$ relative to the surface normal for tri-nickel and penta-nickel complexes. The tilt angles for cobalt and chromium complexes are within

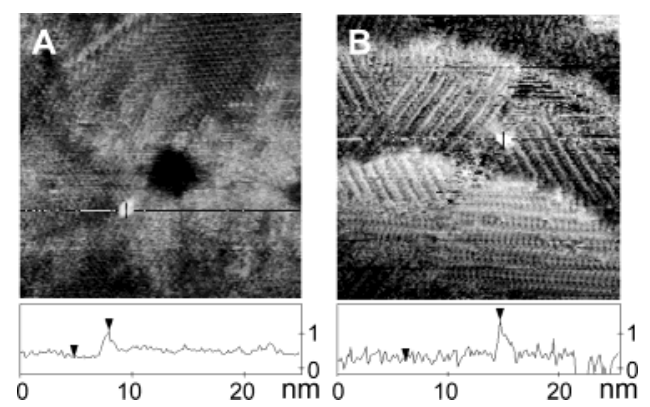

Figure 2. STM images and topographic cross sections of films of metal string complexes. (A) $\left[\mathrm{Ni}_{3}\left(\mu_{3} \text {-dpa }\right)_{4}(\mathrm{NCS})_{2}\right]$ and (B) $\left[\mathrm{Ni}_{5}\left(\mu_{5} \text {-tpda }\right)_{4}{ }^{-}\right.$ $(\mathrm{NCS})_{2}$ ] complexes isolated within $n$-dodecanethiol matrix on $\mathrm{Au}(111)$. The images were recorded with a tip bias of $1.2 \mathrm{~V}$ and a tunneling current of $12 \mathrm{pA}$.

the same range because their IRAS spectra (not shown) are so similar that the tilt angles are indifferentiable by such estimation.

Figure 2A shows a typical STM image of monolayers prepared by insertion of $\mathrm{Ni}_{3}\left(\mu_{3} \text {-dpa }\right)_{4}(\mathrm{NCS})_{2}$ complexes onto preadsorbed $n$-dodecanethiol SAMs. The image exhibits a protrusion surrounded by the lattice identical to the simple $(\sqrt{ } 3$ $\times \sqrt{3}) \mathrm{R} 30^{\circ}$ of $n$-alkanethiol SAMs on $\mathrm{Au}(111) .{ }^{50-55}$ The protrusion is attributed to the result of $\mathrm{Ni}_{3}\left(\mu_{3} \text {-dpa }\right)_{4}(\mathrm{NCS})_{2}$ embedded within the alkanethiol matrix based on the following assessment. First, such a topographic feature is consistent with our expectation that the conductance of the metal string complexes is superior to those of $n$-alkanethiols because in STM images the former appears higher than the latter although it is shorter even when a tilted chain angle of $30^{\circ}$ for $n$-alkanethiols ${ }^{54-56}$ is considered. Second, the height above the dodecanethiol lattice (i.e. $\Delta h_{\mathrm{STM}}$ ) for the protrusions is, in average, $7.8 \pm 1.0 \AA$ for tri-nickel complex (Figure 2A and Table 1) and is raised to $11.3 \pm 0.3 \AA$ for penta-nickel complex (Figure 2B and Table 2). Third, with thinner films of $n$-decanethiol SAMs as the matrix, the averaged difference in height for $\mathrm{Ni}_{3}-$ $\left(\mu_{3} \text {-dpa }\right)_{4}(\mathrm{NCS})_{2}$ is increased correspondingly to $8.3 \pm 0.5 \AA$ (shown in the Supporting Information, Figure S1A). Although we do not rule out the possibility that the protrusions are aggregates of the metal string complexes, it is a consensus for STM studies of surface containing sharp objects that the diameter and shape of the protrusion are dominated by the curvature of the STM tip ${ }^{27,32,57}$ whose geometry, in this case, is imaged by the metal string complexes. Also noticed is that 
TABLE 1: Summary of STM Topographic Heights of the tri-Nuclear Metal String Complexes Relative to $n$-Dodecanethiol Matrix

\begin{tabular}{lccc}
\hline \multirow{2}{*}{$\begin{array}{l}\text { height } \\
\text { difference }\end{array}$} & \multicolumn{3}{c}{$\left[\mathrm{M}_{3}\left(\mu_{3} \text {-dpa }\right)_{4}(\mathrm{NCS})_{2}\right] / \mathrm{C} 12 \mathrm{SH}$} \\
\cline { 2 - 4 } & $\mathrm{Ni3}(14.1 \AA)^{a}$ & $\mathrm{Co} 3(14.0 \AA)^{a}$ & $\mathrm{Cr} 3(14.6 \AA)^{a}$ \\
\hline estimated $^{b}$ & $-3.9 \sim-4.8 \AA$ & $-4.0 \sim-4.9 \AA$ & $-3.5 \sim-4.4 \AA$ \\
$\Delta h_{\text {STM }}$ & $7.8 \pm 1.0 \AA^{c}$ & $10.0 \pm 0.6 \AA$ & $12.8 \pm 0.7 \AA$
\end{tabular}

${ }^{a}$ Shown in the parentheses are corresponding molecular lengths between the terminal sulfur atoms measured from X-ray diffraction (shown in the Supporting Information, Figure S3). For tri-nickel, tricobalt, and tri-chromium complexes, the molecular heights are 13.1$12.2,13.0-12.1$, and $13.5-12.6 \AA$, respectively, based on the tilt angle of $22^{\circ}-30^{\circ}$ estimated from IRAS measurements (Figure 1). ${ }^{b}$ The estimated height difference is calculated by subtraction of the height of metal complexes ${ }^{a}$ by thickness of the surrounding dodecanethiol matrix. The thickness of $n$-dodecanethiol SAMs was estimated to be $14 \sim 15,,^{58,59} \sim 17,,^{60}$ and $\sim 20 \AA^{61}$ by ellipsometry. $17 \AA$ is used in this estimation. ${ }^{c}$ Only images with molecular resolution are used for average. The numbers of films are around 20 for each complex.

TABLE 2: Summary of STM Topographic Heights of the Neutral and Oxidized penta-Nuclear Metal String Complexes Relative to $n$-Dodecanethiol Matrix

\begin{tabular}{lccc}
\hline$\left[\mathrm{M}_{5}\left(\mu_{5} \text {-tpda }\right)_{4}(\mathrm{NCS})_{2}\right] / \mathrm{C} 12 \mathrm{SH}$ & $\begin{array}{c}\mathrm{Ni5} \\
(\AA)\end{array}$ & $\begin{array}{c}\mathrm{Co5} \\
(\AA)\end{array}$ & $\begin{array}{c}\mathrm{Cr} 5 \\
(\AA)\end{array}$ \\
\hline neutral complexes & $11.3 \pm 0.3$ & $14.2 \pm 0.7$ & $16.8 \pm 1.2$ \\
oxidized $(+1)$ complexes & $13.9 \pm 0.4$ & $13.2 \pm 0.4$ & $13.6 \pm 0.8$
\end{tabular}

$\Delta h_{\mathrm{STM}}$ appears not affected by the domain size of the protrusion (shown in the Supporting Information, Figure S3).

It is interesting and of fundamental importance to explore how the metal centers affect the ET probability of the corresponding metal string complexes. The ET probability is compared using the height of protrusions against the same matrix of $n$-dodecanethiol monolayer. Summarized in Table 1 are the nominal heights for tri-nickel, tri-cobalt, and tri-chromium complexes. The values listed in the parentheses are the lengths of the metal string molecules derived from X-ray diffraction measurements. The difference in their physical lengths is within $0.6 \AA$. However, the topographic STM images reveal that the protruding features for the tri-cobalt and the tri-chromium complexes are, respectively, 2.2 and 5.0 $\AA$ higher than that of the tri-nickel complex. Although the electron conducts through the $\mathrm{dpa}^{-}$ligands is a likely pathway, the fact that these complexes have very similar structures and tilt angles relative to the surface normal demonstrates that the difference in ET probability (i.e., difference in $\Delta h_{\mathrm{STM}}$ ) should be ascribed to the difference in their metal-metal interactions.

To further explore the effect of metal-metal interactions on conducting properties, the electronic structures of the metal string complexes are fine-tuned by one-electron oxidation. Oxidized tri-nuclear complexes are relatively less stable than the penta-nuclear ones under ambient conditions, and thus, the latter are employed in this examination. For comparison, both neutral and oxidized penta-nuclear complexes are investigated and the protrusion heights against $n$-dodecanethiol monolayers are tabulated in Table 2. ${ }^{62}$ Inserted within the same matrix, the neutral penta-nuclear complexes appear $3.5 \sim 4.2 \AA$ taller than the corresponding tri-nuclear ones. The heights for the pentacobalt and the penta-chromium complexes are 2.9 and $5.5 \AA$ higher than that of the penta-nickel complex, consistent with the trend observed from that of tri-nuclear ones. Interestingly, the oxidized penta-nickel complex exhibits superior ET efficiency to its neutral form. The protrusions are raised nominally $2.6 \AA$, from $11.3 \pm 0.3 \AA$ to $13.9 \pm 0.4 \AA$, practically the same level as those of the neutral penta-cobalt complex. In the case of oxidized pentacobalt complexes, the height of protrusions drops slightly, right on the lower margin of standard deviation from the average value of the neutral ones. However, the oxidized penta-chromium complex exhibits a considerable decrease of $3.2 \AA$.

Considering that the metal strings coordinate with the same ligands and have almost identical dimensions, the height difference probed by STM should be attributed to ET tunneling through the metal centers, rather than ascribed to ET via the ligands nor dominated by the difference in physical lengths and molecular orientation. Such a phenomenon is, however, not unprecedented. For example, Hipps et al. have shown a strong influence of the metal ion valence configuration $\left(d^{6} \sim d^{9}\right)$ on the observed tunneling images of metalated phthalocyanines ${ }^{42,63}$ and tetraphenylporphyrins ${ }^{43}$ on $\mathrm{Au}(111)$. To correlate the metalmetal interactions with their ET probabilities, we map out electronic structures by the extended Huckel calculations ${ }^{5-7}$ in which one of the prerequisites is filling in the metal-metal bond distances. The metal-metal distances of the nickel strings, including both the neutral ${ }^{4,6}$ and one-electron oxidized ${ }^{9,12}$ forms, are usually symmetric. However, in some cases for tri-cobalt ${ }^{20}$ and tri-chromium ${ }^{14,15}$ complexes, the crystal symmetry of the metal-metal chains and their bond lengths are a function of environment and temperature during crystallization. Therefore, we should decide whether symmetric or unsymmetric ones are plausible to use in this calculation. For the cobalt strings, within the time scale of NMR spectroscopy, only symmetric metalmetal bonds have been found in solution. ${ }^{8,11,22}$ Isolated within the matrix of $n$-alkanethiol SAMs, the metal strings are not in a crystalline state, more similar to those in solution than in crystals. In the case of chromium strings, their symmetry in solution has never been reported in the literature. Calculations show that results utilizing symmetric structure for the neutral chromium strings explains the STM observations better than using the unsymmetric one (vide infra). For the one-electron oxidized chromium strings where only unsymmetric form has been found, ${ }^{7,10,13,17}$ we believe that the structure is unsymmetric. To summarize, symmetric structures are used in the extended Huckel calculations except the one-electron oxidized chromium one.

The parameters for calculations are identical to our previous qualitative studies $^{5-7}$ in which we have concluded that the bond orders for the symmetric and neutral complexes of nickel, cobalt, and chromium are respectively $0,0.5$, and 1.5 , which indicate the degree of electron delocalization and thus the efficiency of electrons conducting through the core atoms of the metal string complexes. Qualitatively speaking, the ascending trend of height difference revealed in Tables 1 and 2 for nickel, cobalt, and chromium complexes correlates well with their bond orders.

Why do the metal string complexes respond so differently upon one-electron oxidation? Extended Huckel calculations of the penta-nuclear complexes and crystal structures of $\left[\mathrm{Ni}_{5}\left(\mu_{5^{-}}\right.\right.$ tpda $\left.)_{4}\left(\mathrm{SO}_{3} \mathrm{CF}_{3}\right)_{2}\right]^{+},\left[\mathrm{Co}_{5}\left(\mu_{5} \text {-tpda }\right)_{4}(\mathrm{NCS})_{2}\right]^{+}$, and $\left[\mathrm{Cr}_{5}\left(\mu_{5} \text {-tpda }\right)_{4} \mathrm{~F}_{2}\right]^{+}$ are examined and compared with the corresponding neutral complexes. Due to the difficulty in growing high quality crystals of $\left[\mathrm{Ni}_{5}\left(\mu_{5} \text {-tpda }\right)_{4}(\mathrm{NCS})_{2}\right]^{+}$and $\left[\mathrm{Cr}_{5}\left(\mu_{5} \text {-tpda }\right)_{4}(\mathrm{NCS})_{2}\right]^{+}$, structures of complexes with other axial ligands are employed in this comparison. The information of the metal-metal bond lengths and the X-ray crystallographic structures are referred to the Supporting Information. Although oversimplified, summarized in Scheme 2 is a self-explanatory illustration. The $\delta$ bonds of penta-chromium complex are regarded as nonbonding orbitals for the helical conformation of the $\operatorname{tpda}^{2-}$ ligand and thus are not shown in the scheme for clarity. For the neutral 


\section{SCHEME 2}

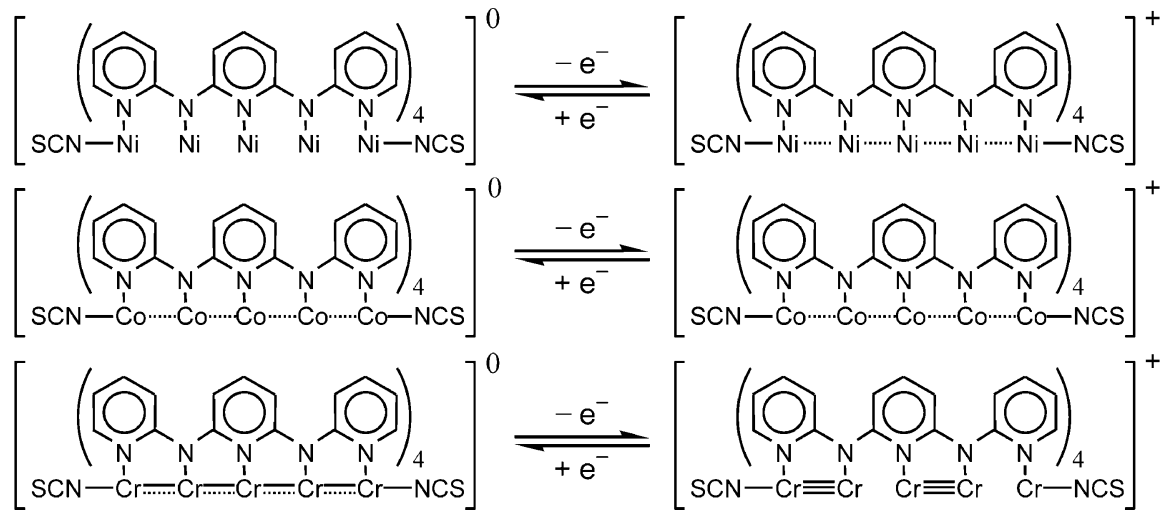

${ }^{a}$ The solid, dotted, and open space between neighboring metal centers represent bond order of $1,0.5$, and 0 , respectively. ${ }^{b} \delta$ bonds $\left(\delta_{\mathrm{n} 1}{ }^{2} \delta_{\mathrm{n} 2}{ }^{2} \delta_{\mathrm{n} 3}{ }^{2}\right)$ for penta-chromium complex are not shown for clarity.

complexes, the d electron configurations for penta-nickel, ${ }^{6}$ pentacobalt, ${ }^{6}$ and penta-chromium ${ }^{7}$ are $\sigma_{1}{ }^{2} \pi_{1}^{4} \sigma_{2}^{2} \pi_{2}{ }^{4} \delta_{\mathrm{n} 1}{ }^{2} \delta_{\mathrm{n} 2}{ }^{2} \pi_{\mathrm{n} 3}{ }^{4}$ $\delta_{\mathrm{n} 3}{ }^{2} \pi^{*}{ }_{4}^{4} \delta_{\mathrm{n} 4}{ }^{2} \pi^{*}{ }_{5}^{4} \delta_{\mathrm{n} 5}{ }^{2} \sigma_{\mathrm{n} 3}{ }^{2} \sigma^{*}{ }_{4}{ }^{2} \sigma^{*}{ }_{5}^{2}, \sigma_{1}{ }^{2} \pi_{1}{ }^{4} \sigma_{2}{ }^{2} \pi_{2}{ }^{4} \delta_{\mathrm{n} 1}{ }^{2} \delta_{\mathrm{n} 2}{ }^{2} \pi_{\mathrm{n} 3}{ }^{4} \delta_{\mathrm{n} 3}{ }^{2}-$ $\pi^{*}{ }_{4}^{4} \delta_{\mathrm{n} 4}{ }^{2} \pi^{*}{ }_{5}^{4} \delta_{\mathrm{n} 5}{ }^{2} \sigma_{\mathrm{n} 3}{ }^{1}$, and $\sigma_{1}{ }^{2} \sigma_{2}{ }^{2} \pi_{1}{ }^{4} \pi_{2}{ }^{4} \delta_{\mathrm{n} 1}{ }^{2} \delta_{\mathrm{n} 2}{ }^{2} \delta_{\mathrm{n} 3}{ }^{2} \pi_{\mathrm{n}(\mathrm{dxy})}{ }^{1} \pi_{\mathrm{n}(\mathrm{dyz})}{ }^{1}$, respectively (where subscript $\mathrm{n}$ denotes nonbonding). After one electron oxidation, the bond order for penta-nickel complexes is increased and stays the same for penta-cobalt complexes, consistent with their dissimilar response of protrusion heights in STM measurements. Regarding the marginal decrease in protrusion heights for $\left[\mathrm{Co}_{5}\left(\mu_{5} \text {-tpda }\right)_{4}(\mathrm{NCS})_{2}\right]^{+}$, the $\mathrm{X}$-ray crystal structure reveals that all of the $\mathrm{Co}-\mathrm{Co}$ bond lengths are slightly longer than those in the neutral form by about $0.01 \sim 0.02 \AA$. Although insignificant, the increase in bond lengths suggests a relatively smaller internuclei interaction and thus a slight decrease in ET probability, even though the overall bond order remains unchanged upon one-electron oxidization. In the case of penta-chromium, the oxidized complex develops two sets of very dissimilar $\mathrm{Cr}-\mathrm{Cr}$ distances ${ }^{7}$ where the short and long ones are consistent with quadruple bonds and with no metal-metal bonding interaction, respectively. Therefore, the substantial reduction in heights observed by STM measurements is attributed to the switch of electronic structures from delocalized to localized conformation.

\section{Conclusion}

IRAS measurements indicate that the metal string complexes chemisorb on Au substrate via the sulfur-gold interactions and that the tilt angles relative to the surface normal are similar to that of the dodecanethiol matrix. We have shown the effect of metal-metal interactions on the STM topographic height, a result of ET via tunneling through the metal string complexes. For complexes with symmetric crystal structures, such as the neutral tri- and penta-nuclear complexes, the attenuation of their ET probability is dependent on the number of delocalized electrons or the metal-metal bond order. In the case of pentachromium where, upon one-electron oxidation, the symmetric bonding scheme is altered significantly to an unsymmetric structure, the oxidized form exhibit inferior ET efficiency due to electron localization. The examples of penta-nickel and pentachromium complexes demonstrate that their ET properties can be manipulated and shed light on the potential applications such as molecular switches.

Acknowledgment. The authors thank the National Science Council and the Ministry of Education of the Republic of China (Taiwan, R.O.C.) for financial support.
Supporting Information Available: Additional information as noted in the text, including STM images of $\left[\mathrm{Ni}_{3}\left(\mu_{3} \text {-dpa }\right)_{4}{ }^{-}\right.$ $\left.(\mathrm{NCS})_{2}\right],\left[\mathrm{Co}_{3}\left(\mu_{3} \text {-dpa }\right)_{4}(\mathrm{NCS})_{2}\right],\left[\mathrm{Co}_{5}\left(\mu_{5} \text {-tpda }\right)_{4}(\mathrm{NCS})_{2}\right],\left[\mathrm{Cr}_{3}\left(\mu_{3}-\right.\right.$ dpa $\left.)_{4}(\mathrm{NCS})_{2}\right],\left[\mathrm{Cr}_{5}\left(\mu_{5} \text {-tpda }\right)_{4}(\mathrm{NCS})_{2}\right]$ (Figure S1), $\left[\mathrm{Ni}_{5}\left(\mu_{5} \text {-tpda }\right)_{4-}\right.$ $\left.(\mathrm{NCS})_{2}{ }^{+}\right],\left[\mathrm{Co}_{5}\left(\mu_{5} \text {-tpda }\right)_{4}(\mathrm{NCS})_{2}{ }^{+}\right],\left[\mathrm{Cr}_{5}\left(\mu_{5} \text {-tpda }\right)_{4}(\mathrm{NCS})_{2}{ }^{+}\right]$(Figure $\mathrm{S} 2)$, distribution of STM apparent height against domain size (Figure S3), detailed crystal data of $\left[\mathrm{Ni}_{3}\left(\mu_{3}-\mathrm{dpa}\right)_{4}(\mathrm{NCS})_{2}\right],\left[\mathrm{Co}_{3}-\right.$ $\left.\left(\mu_{3} \text {-dpa }\right)_{4}(\mathrm{NCS})_{2}\right],\left[\mathrm{Cr}_{3}\left(\mu_{3} \text {-dpa }\right)_{4}(\mathrm{NCS})_{2}\right]$ (Figure S4), $\left[\mathrm{Ni}_{5}\left(\mu_{5^{-}}\right.\right.$ tpda $\left.)_{4}\left(\mathrm{H}_{2} \mathrm{O}\right)\left(\mathrm{BF}_{4}\right)\right]^{2+}\left(\mathrm{BF}_{4}\right)_{2}{ }^{2-},\left[\mathrm{Co}_{5}\left(\mu_{5} \text {-tpda }\right)_{4}(\mathrm{NCS})_{2}\right]^{+}\left(\mathrm{ClO}_{4}\right)^{-}$, $\left[\mathrm{Cr}_{5}\left(\mu_{5} \text {-tpda }\right)_{4} \mathrm{~F}_{2}\right]^{+}\left(\mathrm{BF}_{4}\right)^{-}$(Figure S5), cyclic voltammograms of one-electron redox for the pentanuclear complexes (Figure S6), a summarized metal-metal bond distances (Table S1), and MO diagrams of $\left[\mathrm{Co}_{5}\left(\mu_{5} \text {-tpda }\right)_{4}(\mathrm{NCS})_{2}\right]$ and $\left[\mathrm{Cr}_{5}\left(\mu_{5} \text {-tpda }\right)_{4^{-}}\right.$ $(\mathrm{NCS})_{2}$ ] (Figure S7). This material is available free of charge via the Internet at http://pubs.acs.org.

\section{References and Notes}

(1) Yang, E.-C.; Cheng, M.-C.; Tsai, M.-S.; Peng, S.-M. J. Chem. Soc., Chem. Commun. 1994, 2377-2378.

(2) Lai, S.-Y.; Lin, T.-W.; Chen, Y.-H.; Wang, C.-C.; Lee, G.-H.; Yang, M.-H.; Leung, M.-K.; Peng, S.-M. J. Am. Chem. Soc. 1999, 121, 250251.

(3) Peng, S.-M.; Wang, C.-C.; Jang, Y.-L.; Chen, Y.-H.; Li, F.-Y.; Mou, C.-Y.; Leung, M.-K. J. Magn. Magn. Mater. 2000, 209, 80-83.

(4) Peng, C.-H.; Wang, C.-C.; Lee, H.-C.; Lo, W.-C.; Lee, G.-H.; Peng, S.-M. J. Chin. Chem. Soc. 2001, 48, 987-996.

(5) Shieh, S.-J.; Chou, C.-C.; Lee, G.-H.; Wang, C.-C.; Peng, S.-M. Angew. Chem., Int. Ed. Engl. 1997, 36, 56-58.

(6) Wang, C.-C.; Lo, W.-C.; Chou, C.-C.; Lee, G.-H.; Chen, J.-M.; Peng, S.-M. Inorg. Chem. 1998, 37, 4059-4065.

(7) Chang, H.-C.; Li, J.-T.; Wang, C.-C.; Lin, T.-W.; Lee, H.-C.; Lee, G.-H.; Peng, S.-M. Eur. J. Inorg. Chem. 1999, 1243-1251.

(8) Yeh, C.-Y.; Chou, C.-H.; Pan, K.-C.; Wang, C.-C.; Lee, G.-H.; Su, Y. O.; Peng, S.-M. J. Chem. Soc., Dalton Trans. 2002, 2670-2677.

(9) Yeh, C.-Y.; Chiang, Y.-L.; Lee, G.-H.; Peng, S.-M. Inorg. Chem. 2002, 41, 4096-4098.

(10) Clerac, R.; Cotton, F. A.; Daniels, L. M.; Dunbar, K. R.; Murillo, C. A.; Pascual, I. Inorg. Chem. 2000, 39, 752-756.

(11) Clerac, R.; Cotton, F. A.; Dunbar, K. R.; Lu, T.; Murillo, C. A.; Wang, X. J. Am. Chem. Soc. 2000, 122, 2272-2278.

(12) Berry, J. F.; Cotton, F. A.; Daniels, L. M.; Murillo, C. A. J. Am. Chem. Soc. 2002, 124, 3212-3213.

(13) Berry, J. F.; Cotton, F. A.; Daniels, L. M.; Murillo, C. A.; Wang, X. Inorg. Chem. 2003, 42, 2418-2427.

(14) Cotton, F. A.; Daniels, L. M.; Murillo, C. A.; Wang, X. Chem. Commun. 1999, 2461-2462.

(15) Clerac, R.; Cotton, F. A.; Daniels, L. M.; Dunbar, K. R.; Murillo, C. A.; Pascual, I. Inorg. Chem. 2000, 39, 748-751.

(16) Clerac, R.; Cotton, F. A.; Daniels, L. M.; Dunbar, K. R.; Kirschbaum, K.; Murillo, C. A.; Schultz, A. J.; Wang, X. J. Am. Chem. Soc. 2000, 122, 6226-6236.

(17) Cotton, F. A.; Daniels, L. M.; Murillo, C. A.; Pascual, I. Inorg Chem. Commun. 1998, 1, 1-3. 
(18) Cotton, F. A.; Daniels, L. M.; Murillo, C. A.; Pascual, I. J. Am. Chem. Soc. 1997, 119, 10223-10224.

(19) Cotton, F. A.; Daniels, L. M.; Lu, T.; Murillo, C. A.; Wang, X. J. Chem. Soc., Dalton Trans. 1999, 517-518.

(20) Clerac, R.; Cotton, F. A.; Daniels, L. M.; Dunbar, K. R.; Murillo, C. A.; Wang, X. Inorg. Chem. 2001, 40, 1256-1264.

(21) Clerac, R.; Cotton, F. A.; Jeffery, S. P.; Murillo, C. A.; Wang, X. Inorg. Chem. 2001, 40, 1265-1270.

(22) Cotton, F. A.; Murillo, C. A.; Wang, X. Inorg. Chem. 1999, 38 , 6294-6297.

(23) Rohmer, M.-M.; Benard, M. J. Am. Chem. Soc. 1998, 120, 93729373.

(24) Rohmer, M.-M.; Strich, A.; Benard, M.; Malrieu, J.-P. J. Am. Chem. Soc. 2001, 123, 9126-9134.

(25) Rohmer, M.-M.; Benard, M. J. Cluster Sci. 2002, 13, 333-353.

(26) Leung, M.-k.; Mandal, A. B.; Wang, C.-C.; Lee, G.-H.; Peng, S.M.; Cheng, H.-L.; Her, G.-R.; Chao, I.; Lu, H.-F.; Sun, Y.-C.; Shiao, M.Y.; Chou, P.-T. J. Am. Chem. Soc. 2002, 124, 4287-4297.

(27) Bumm, L. A.; Arnold, J. J.; Cygan, M. T.; Dunbar, T. D.; Burgin, T. P.; Jones, L., II.; Allara, D. L.; Tour, J. M.; Weiss, P. S. Science 1996, $271,1705-1707$.

(28) Bumm, L. A.; Arnold, J. J.; Dunbar, T. D.; Allara, D. L.; Weiss, P. S. J. Phys. Chem. B 1999, 103, 8122-8127.

(29) Donhauser, Z. J.; Mantooth, B. A.; Kelly, K. F.; Bumm, L. A. Monnell, J. D.; Stapleton, J. J.; Price, D. W. Jr.; Rawlett, A. M.; Allara, D. L.; Tour, J. M.; Weiss, P. S. Science 2001, 292, 2303-2307.

(30) Ishida, T.; Mizutani, W.; Aya, Y.; Ogiso, H.; Sasaki, S.; Tokumoto, H. J. Phys. Chem. B 2002, 106, 5886-5892.

(31) Wold, D. J.; Haag, R.; Rampi, M. A.; Frisbie, C. D. J. Phys. Chem. $B$ 2002, 106, 2813-2816.

(32) Leatherman, G.; Durantini, E. N.; Gust, D.; Moore, T. A.; Moore, A. L.; Stone, S.; Zhou, Z.; Rez, P.; Liu, Y. Z.; Lindsay, S. M. J. Phys. Chem. B 1999, 103, 4006-4010.

(33) Rawlett, A. M.; Hopson, T. J.; Nagahara, L. A.; Tsui, R. K.; Ramachandran, G.; Lindsy, S. M. Appl. Phys. Lett. 2002, 81, 3043-3045.

(34) Xu, B.; Tao, N. J. Science 2003, 301, 1221-1223.

(35) Wold, D. J.; Frisbie, C. D. J. Am. Chem. Soc. 2001, 123, 55495556.

(36) Wold, D. J.; Frisbie, C. D. J. Am. Chem. Soc. 2000, 122, 29702971.

(37) Cui, X. D.; Primak, A.; Zarate, X.; Tomfohr, J.; Sankey, O. F.; Moore, A. L.; Moore, T. A.; Gust, D.; Harris, G.; Lindsay, S. M. Science 2001, 294, 571-574.

(38) Holmlin, R. E.; Ismagilov, R. F.; Haag, R.; Mujica, V.; Ratner, M. A.; Rampi, M. A.; Whitesides, G. M. Angew. Chem., Int. Ed. Engl. 2001, 40, 2316-2320

(39) Holmlin, R. E.; Haag, R.; Chabinyc, M. L.; Ismagilov, R. F.; Cohen, A. E.; Terfort, A.; Rampi, M. A.; Whitesides, G. M. J. Am. Chem. Soc. 2001, 123, 5075-5085.

(40) Selzer, Y.; Salomon, A.; Cahen, D. J. Am. Chem. Soc. 2002, 124 , 2886-2887

(41) Nazin, G. V.; Qiu, X. H.; Ho, W. Science 2003, 302, 77-81.
(42) Lu, X.; Hipps, K. W. J. Phys. Chem. B 1997, 101, 5391-5396.

(43) Scudiero, L.; Barlow, D. E.; Hipps, K. W. J. Phys. Chem. B 2000 $104,11899-11905$

(44) Pemble, M. In Surface Analysis: the Principal Techniques; Vickerman, J. C., Ed.; John Wiley \& Sons: New York, 1997; pp 278282.

(45) Zamlynny, V.; Zawisza, I.; Lipkowski, J. Langmuir 2003, 19, 132145.

(46) Li, N.; Zamlynny, V.; Lipkowski, J.; Henglein, F.; Pettinger, B. J. Electroanal. Chem. 2002, 524-525, 43-53.

(47) Li, X.; Gewirth, A. A. J. Am. Chem. Soc. 2003, 125, 11674-11683.

(48) Greenler, R. G. J. Chem. Phys. 1966, 44, 310-315.

(49) The angles between the axis of metal cores and the directions normal to the pyridyl ring planes are $67^{\circ}$ and $71^{\circ}$ for tri-cobalt complex; $68^{\circ}$ and $72^{\circ}$ for tri-chromium complex; $72^{\circ}, 74^{\circ}$, and $70^{\circ}$ for penta-cobalt complex; $72^{\circ}, 74^{\circ}$, and $72^{\circ}$ for penta-chromium complex.

(50) Delamarche, E.; Michel, B.; Gerber, C.; Anselmetti, D.; Guntherodt, H.-J.; Wolf, H.; Ringsdorf, H. Langmuir 1994, 10, 2869-2871.

(51) Schonenberger, C.; Sondag-Huethorst, J. A. M.; Jorritsma, J.; Fokkink, L. G. J. Langmuir 1994, 10, 611-614.

(52) Poirier, G. E. Chem. Rev. 1997, 97, 1117-1127.

(53) Zeng, C.; Li, B.; Wang, B.; Wang, H.; Wang, K.; Yang, J.; Hou, J. G.; Zhu, Q. J. Chem. Phys. 2002, 117, 851-856.

(54) Ulman, A. Chem. Rev. 1996, 96, 1533-1554.

(55) Schreiber, F. Prog. Surf. Sci. 2000, 65, 151-257.

(56) Laibinis, P. E.; Whitesides, G. M.; Allara, D. L.; Tao, Y.-T.; Parikh, A. N.; Nuzzo, R. G. J. Am. Chem. Soc. 1991, 113, 7152-7167.

(57) Kepler, K. D.; Gewirth, A. A. Surf. Sci. 1994, 303, 101-113.

(58) Bain, C. D.; Troughton, E. B.; Tao, Y.-T.; Evall, J.; Whitesides,

G. M.; Nuzzo, R. G. J. Am. Chem. Soc. 1989, 111, 321-335.

(59) Meuse, C. W. Langmuir 2000, 16, 9483-9487.

(60) Collins, R. W.; Allara, D. L.; Kim, Y.-T.; Lu, Y.; Shi, J. In Characterization of Organic Thin Films; Ulman, A., Ed.; ButterworthHeinemann: Boston, MA, 1995; pp 48-49.

(61) Porter, M. D.; Bright, T. B.; Allara, D. L.; Chidsey, C. E. D. J. Am. Chem. Soc. 1987, 109, 3559-3568.

(62) From the redox potentials obtained from cyclic voltammograms (CVs) of the metal strings, we believe that their oxidation states remain unchanged after chemisorption onto the $\mathrm{Au}(111)$ substrate. The Fermi energy of $\mathrm{Au}(111)$ is $5.31 \mathrm{eV}$, (Handbook of Chemistry and Physics, 67th ed.; CRC Press: Boca Raton, FL, 1986; p E-89) corresponding to 0.81 V versus NHE (Bard, A. J.; Faulkner, L. R. Electrochemical Method, 2nd ed.; Wiley: New York, 2001; p 54). For the one-electron oxidized compounds to be reduced by $\mathrm{Au}(111)$, their redox potential should be more positive than $0.81 \mathrm{~V}$ versus NHE. CVs (Figure S6) show that the one-electron redox potentials for penta-nickel, penta-cobalt, and penta-chromium complexes are respectively $0.573,0.269$, and $0.192 \mathrm{~V}$ versus NHE, at least $237 \mathrm{mV}$ smaller than the Fermi energy of $\mathrm{Au}(111)$. Reduction of the one-electron oxidized metal strings by $\mathrm{Au}(111)$ substrate is, therefore, not favorable.

(63) Lu, X.; Hipps, K. W.; Wang, X. D.; Mazur, U. J. Am. Chem. Soc. 1996, $118,7197-7202$ 